\title{
In search of a nativist theory of second language acquisition
}

\section{Johann L.van der Walt}

This article illustrates the search for a theory of second language acquisition. It is the task of the applied linguist to investigate any discipline which can shed light on this problem. The article investigates the field of theoretical linguistics, in particular Chomsky's Universal Grammar, functional linguistics, and cognitive learning theory for answers to the question of how a second language is acquired.

Hierdie artikel illustreer die soeke na 'n teorie van tweedetaalverwerwing. Dit is die taak van die toegepaste linguis om enige dissipline te ondersoek wat lig op hierdie probleem kan werp. Daar word gekyk na die teoretiese linguistiek, en veral na Chomsky se Universele Grammatika, die funksionele linguistiek, en kognitiewe leerteorie vir antwoorde op die vraag hoe 'n tweede taal verwerf word.

\section{INTRODUCTION}

A teacher's beliefs about second language acquisition will influence and determine his approach to the teaching task. Second language acquisition theory is therefore a central concem in second language teaching. The assumption is: if we know how a language is acquired, we shall know how to teach it. It is the task of the applied linguist to provide the language teacher with such a theory. The problem, however, is that more than forty theories of second language acquisition have been advanced (Larsen-Freeman and Long 1991:227). The pursuit of such a theory is therefore a problematical issue.

The purpose of this article is to illustrate the search for a theory of second language acquisition (SLA). Because language acquisition is such a complex issue, it is necessary to approach SLA theory from a number of different perspectives. The article will also serve to illustrate how the applied linguist goes about his task.

\section{NATIVIST AND ENVIRONMENTALIST THEORIES}

A major question in the approach to SLA theory is to what extent the learner is influenced by cognitive and linguistic processes and by cognitive and linguistic processes. This question has led to a number of different theories of SLA, which may usefully be divided into two general types:

in the first place there are nativist theories, which purport to explain acquisition by positing an innate biological endowment which makes language acquisition possible; 
in the second place there are environmentalist theories, which emphasize the influence of the broader social context on language acquisition. They hold that an organism's nurture, or experience, is of more importance to development than its nature, or innate contributions.

Chomsky (1976:13) points out that every theory of learning incorporates an innateness hypothesis. Even Behaviourism attributes to the child the ability to form associations of stimulus and response. All learning theories in fact have to take into account both the learner and the situation; they are therefore all interactionist to some extent (Cook 1985:7). Theories differ in how they strike a balance between cognition and the environment; the person and the situation. For example, Chomsky comes down heavily at the learner end; Behaviourism at the situational end.

I shall focus on the nativist theories in this article, and consider those system-internal factors and processes which account for SLA. This is the area where the wonder of language acquisition becomes clear. Language acquisition has been described as "the greatest intellectual feat any one of us is ever required to perform" (Bloomfield 1933:29), and the word "mystery" is often used in this regard (e.g. Tarone 1990:393; Gass 1989:500).

\section{LINGUISTIC THEORY}

The place to start the search for a theory of second language acquisition is theoretical linguistics. Language teachers have always regarded linguistics as something of a mother discipline. Johnson (1982:10) points out that "language teachers have always looked to the linguist for guidance on how to teach languages". We assume that there is a relationship between formal linguistics and language pedagogy. In this regard it is necessary to be clear about the goal of linguistics. Linguists nowadays are not concerned with the organisation of language data so much as the nature of the organising power that is capable of handling such data. The goal of linguistics is an understanding of the workings of the human mind. Chomsky has in fact always argued that linguistics is a branch of cognitive psychology. Linguists investigate the internal logic of language structure, and the nature of the knowledge which enables a learner to achieve creative control of language. Linguists therefore seek to explain what constitutes knowledge of language, and how such knowledge is acquired.

A problem facing the applied linguist who turns to linguistic theory is that there are many competing schools of thought and approaches in this field: for example, structuralism, tagmemics, scale and category, generative grammar, generative semantics, functionalism and speech act theory. The most influential school is generative grammar, but even it contains a bewildering variety of frameworks for the description of syntax, each with its own aims, research methods and technical vocabulary. Since the mid-1980s three alternative generative models have emerged, namely Chomsky's Government Binding Theory, which is a major extension of his Extended Standard Theory; Generalized Phrase Structure Grammar; and Lexical-Functional Grammar. The problem for the applied linguist is: which of these frameworks must he adopt for his research?

The dominant trend in linguistic theory has been to adopt the assumptions of Chomsky's theory. Two of the questions addressed by Chomsky are: What constitutes knowledge of a language? and, how is such knowledge acquired? His theory of a Universal Grammar (UG) is one of the most promising recent developments in pursuit of a principled characterization of the L2 acquisition process. 


\section{UNIVERSAL GRAMMAR}

Any scientific study must first establish the domain of inquiry. The first question generative grammarians ask is: what is it that is acquired? It obviously involves the acquisition of knowledge. Some of the knowledge of a language is, in fact, not acquired, but is innate. The domain of SLA inquiry within a generative framework is the innate knowledge of a language. This domain does not include the linguistic behaviour of learners. Generative grammarians point out that humans have knowledge of a language quite apart from their ability to use that knowledge. It is therefore important to distinguish between knowledge and ability. The term used for knowledge is competence, and Chomsky and his followers are in search of a competence theory, not a performance theory.

Chomsky maintains that language constitutes a separate faculty which cannot be explained with reference to a general cognitive system. He therefore rejects explanations of language acquisition within a Piagetian framework. He says that the acquisition of a grammar is only possible if it is guided by some kind of innate structure, specifically linguistic in nature. This is called a Universal Grammar. The linguistic competence of an adult is extremely complex, intricate and subtle, and there is no way that the child can acquire this knowledge without prior knowledge of some kind. Since this knowledge is not based on the child's experience of the world, it must come from some property in his mind. The child knows things about language he could not have learnt from the environment (Cook 1985:3), and important aspects of language are not strictly speaking learnable.

There is a mismatch between the input that the child receives and the system actually acquired. This has been called the projection or logical problem of language acquisition. The heart of the argument for an innate linguistic capacity is the fact that a number of aspects of language are underdetermined by the input: the grammar that underlies the adult's actual language use goes far beyond the actual sentences that an individual learner may happen to have been exposed to (White 1989:5). The following is an example of the unconscious knowledge of the adult speaker of English.

In informal spoken English the sequence want to can contract to wanna, e.g.:

I want to go > I wanna go

Who do you want to see? $>$ Who do you wanna see?

The native speaker of English knows unconsciously when contraction is possible and when it is not. For example, it is possible in the sentence

Who do you want to see?

but impossible in

Who do you want to feed the dog?

In addition, the native speaker also knows that an uncontracted sentence such as

Teddy is the man I want to succeed

is ambiguous (it can have two meanings, viz "I want to succeed Teddy" or "I want Teddy to succeed at something"). He also knows that the contracted sentence 
Teddy is the man I wanna succeed

is not ambiguous (it means only "I want Teddy to succeed").

It is difficult for the learner to arrive at the correct knowledge of the distribution and interpretation of wanna from generalizations from the language he hears. One expects false analogies to be made, but this does not happen. Most adults arrive at this knowledge automatically and subconsciously.

The acquisition of wanna can be explained by means of principles of Universal Grammar. One such principle states that wh-questions are formed by the movement of the wh-word from an underlying position to the front of the sentence. An empty category, called a trace, marks the position from which the wh-question has moved, for example

- Do you want to see him? > Who do you want to see _?

Do you want him to feed the dog? $>$ Who do you want _ to feed the dog?

The UG principle says that if a trace $($ intervenes between want and to contraction is impossible. Therefore, in

Who do you want _to feed the dog?

the trace intervenes between want and to, and contraction is impossible: one doesn't say "Who do you wanna feed the dog?". In the sentence "Teddy is the man I want to succeed" the trace also intervenes, making the sentence ambiguous. In the sentence "Teddy is the man I wanna succeed" the trace does not intervene, and the sentence is not ambiguous.

None of this information is obviously available in the input to which a leamer is exposed, since traces are an abstraction. The fact that wh-movement leaves a trace and that this trace blocks the operation of certain rules is knowledge derived from Universal Grammar, and not input alone, or from any general non-linguistic cognitive principles (White 1989:6-7).

It is therefore argued that the language properties inherent in the human mind consist of an abstract, but linguistically significant, system which underlies all natural language. These properties make up what is called the Universal Grammar. It is not composed of particular rules of a particular grammar, but consists of a set of general linguistic principles and a set of parameters.

The general principles make up a mental grammar, and this grammar consists of linguistic principles which apply to all grammars. Chomsky (1980:69) says that "Universal Grammar is taken to be a set of properties, conditions, or whatever, that constitutes the "initial" state of the language learner, hence the basis on which khowledge of language develops". These principles constrain the tange of hypotheses that a child can accommodate about the structure of its language. The child builds up the best grammar possible on the basis of what is cognitively possible at any particular maturational point (McLaughlin 1987: 9). Although the principles of Universal Grammar (UG) are universal, not every principle operates in every language. An example bf a principle is the one which has just been referred to, which explains the wanna-contraction, and which controls the formation of wh-questions. This principle is called the Empty Category Principle. Other principles include the Right Roof Constraint, the Projection Principle, and Subjacency. 
In addition, a limited number of options are built into UG. The set of principles makes available a set of parameters, some of which are left open. Universal Grammar therefore sets the limits within which human language can vary. Values for parameters are set for each language; these are known as parameter settings. Language acquisition is therefore a process whereby the child sets the values of the parameters of the principles of UG (McLaughlin 1987:94). The function of the input data in language acquisition is to help fix one of the possible settings. This is called triggering. In other words, the input helps the learner to make the choice between the various built-in settings. Parameters remain "open" until they are set by experience. An example is the Pro-Drop parameter, which explains the phenomenon that there are certain languages, such as Italian and Spanish, which allow subject pronouns to be omitted (White 1989:84-85).

The principles plus parameter values set make up the core grammar of the learner. Two kinds of grammar are distinguished: core and peripheral. The core grammar refers to those parts of the language that have "grown" in the child through the interaction of the UG with the language environment. Peripheral grammar consists of those elements that are derived from the history of the language, that have been borrowed from other languages, or that have arisen accidentally (McLaughlin 1987:95). The rules of the core grammar are thought to be unmarked and those of the peripheral grammar are marked. Markedness theory has been invoked to propose that marked properties of language are harder to learn than unmarked ones and will emerge later (White 1989:117). Only minimal exposure is needed to acquire a core rule, while peripheral or marked rules need to be learned on the basis of positive evidence of their existence in the grammar (McLaughlin 1987:97).

\section{UG AND SECOND LANGUAGE ACQUISITION}

The question now arises: does this theory shed any light on the problem of second language acquisition? Research conducted within the Creative Construction hypothesis in the 1970s suggests that the language faculty which constrains the L1 acquisition process also constrains the L2 acquisition process (Flynn 1985:100). So the question is: can a parallel case be made for $\mathrm{L} 2$ acquisition?

The first question that has to be considered is whether there is a mismatch between the input that L2 learners receive and their ultimate attainment, i.e. whether there is also a logical or projection problem. The many successful second language speakers who have acquired the language naturalistically are a case in point. These speakers often reveal a very sophisticated grammar which contains structures that native speakers could not have demonstrated to them, and this makes one suspect that there is indeed a logical problem in second language acquisition, i.e. that the second language speaker's knowledge derives from some property of the mind.

If one accepts this, then two hypotheses reveal themselves for testing:

- that UG is available in $\mathrm{L} 2$ acquisition, or

- that UG is unavailable in L2 acquisition.

White $(1989: 51)$ points out that each of these hypotheses makes different predictions, e.g. the UG hypothesis predicts that L2 learners should attain knowledge of ungrammaticality and ambiguity in the L2 and observe principles of UG. This knowledge would be obtainable only from UG; the UG is therefore still accessible. The UG-is-dead hypothesis predicts that $\mathrm{L} 2$ leamers will not be able to attain this kind of knowledge (it assumes that $\mathrm{L} 1$ acquisition is radically different from $\mathrm{L} 2$ acquisition). 
The strength of this theory is that it is testable. A number of empirical investigations have been done, using tasks such as grammaticality judgement tasks, act-out tasks, and avoidance tracing to test for UG functioning. A number of studies (cf. White 1989) suggest that UG principles are available to the $\mathrm{L} 2$ learner and that parameter resetting is possible. It is clear that some learners do attain complex and subtle knowledge which does not derive solely from the L1; this is unexplained if L2 learning proceeds only by means of general cognitive strategies such as problem-solving and hypothesis-testing, and suggests that UG must be involved. The UG hypothesis is therefore supported. However, a limited number of parameters have been studied, and there are also methodological concerns about some of the studies. There are also findings which claim the opposite, namely that the learner does not have direct access to the Universal Grammar (e.g. Clahsen and Muysken 1986). The claim of total equivalence of UG in L1 and L2 is not supported unconditionally.

At his moment no unequivocal answer about the role of UG in SLA can be given (White 1989:174). At best we can say that there is partial access to UG in L2 acquisition.

\section{A FUNCTIONAL LINGUISTIC PERSPECTIVE}

It is unlikely that other cognitive areas will not play any role in the L2 acquisition process. One of the questions which remain is to what extent UG may interact with other cognitive domains in L2 acquisition. Needless to say, UG theory has been subjected to a number of criticisms (e.g. Love 1990; Ellis 1990; McLaughlin 1987; Larsen-Freeman and Long 1991). A major problem which the classroom-oriented researcher faces is that UG is concerned with the acquisition of linguistic competence only, as I have pointed out. Chomsky distinguishes the idea of "knowledge", which is static, from the idea of "ability to use knowledge" (or performance), which is dynamic. He does not address performance, or language use, and how competence in the use of the language develops. There are linguists who reject the distinction between competence and performance (e.g. Halliday). Other linguists (in fact, sociolinguists) have attempted to extend the notion of competence to include all rule-systems which describe our knowledge of language and how to operate with it (e.g. Hymes' notion of communicative competence). These theories take into account the close connection between language and social relationships. Such theories, known as functional theories of language, study language in relation to the situations in which it is used. In a functional approach the object of study is the knowledge of how to produce and comprehend language, and competence is seen as the ability to do something, to use language for communicative purposes.

This approach to language is much closer to the concerns of the language teacher. He is interested in the question: how do learners acquire the capacity to perform accurately and fluently in the second language? Ellis (1990:175) says: "Teachers are concerned with both how knowledge is acquired and, crucially, with the learner's ability to make use of this knowledge." In this regard, Taylor (1988:166) makes an important new distinction. He suggests that the term "competence" be used for "knowledge", while "proficiency" be used for "ability to use knowledge".

UG goes some way towards explaining how aspects of L2 knowledge are acquired in the first place. What is further required is a theory of proficiency; how learners develop the ability to use their L2 knowledge.

\section{A COGNITIVE PERSPECTIVE}

Such an explanation may be found in cognitive learning theory. A number of cognitive theories have been advanced, and some have been applied to second language acquisition. 
Cognitive theory views language learning as a complex skill which involves the use of various information-processing techniques to overcome limitations in mental capacity which inhibit performance. The theory tries to account for the development of the ability to use knowledge; how learners achieve control over new information. One such account distinguishes between controlled and automatic processing (McLaughlin 1987:134; Ellis 1990:176). Controlled processing is used initially in the learning of a new complex cognitive skill; it requires attention and extensive practice; it takes time; and can take place with or without any conscious awareness on the part of the learner. This processing later becomes automatic and effortless, i.e. information which was initially only available for use through controlled processing can then be handled spontaneously. Another theory, that of Anderson (1983), holds that conscious attention which can be explicitly formulated by the learners is an essential first step before automatization can take place.

The acquisition of new information leads to a restructuring of the learner's knowledge system: as learning takes place, the existing system is modified in order to take account of the new information (Ellis 1990:178; McLaughlin 1990).

A number of researchers have applied cognitive learning theory to second language acquisition. One such attempt is Bialystok's (1988). She argues that language is processed by the human mind in the same way as other kinds of information. Her model distinguishes between an analysed factor and an automatic factor. The analysed factor concerns the extent to which the learner is aware of the structure of his linguistic knowledge. In the early stages of L2 learning, the learner is not aware of the structure and organisation of knowledge; later on awareness increases, enabling the learner to identify the formal structure. Bialystok (1988:40) points out that the degree of analycity is not linked to consciousness and is not explicitly represented in the mind of the learner. She says that "it is erroneous to equate analysed knowledge with articulated knowledge, or knowledge of rules". Metalingual knowledge, however, is possible. The automatic factor concerns the relative access which the learner has to knowledge. Knowledge gains in automaticity as learning takes place, and automaticity is achieved through practice. The analysed and the automatic factors develop independently of each other; however, the simultaneous development of both dimensions is difficult - learners are likely to concentrate on one factor or the other. For example, some learners will go for automaticity; others will concentrate on analysing their knowledge by breaking down formulaic expressions acquired as unanalysed. Learning style and the type of input in the classroom will also influence which factor is emphasised (Ellis, 1990:179-180).

Cognitive theory does not provide a complete theory of language development. The theory provides a partial account only. For example, it cannot account for the fact that there are acquisitional sequences which are immune to instruction. Instruction cannot change the order in which certain developmental structures are acquired. Thus the basic assumption of cognitive theory, that language learning and use are not different in kind from other kinds of skill learning, is not fully justified (Ellis 1990:182).

Cognitive theory is also not able to explain the role of explicit knowledge in language acquisition. It is true that many leamers - especially adolescents and adults - make use of problem-solving skills in order to derive conscious rules about the form of the L2 grammar. This typically happens in formal instruction situations. Ellis (1990:183) points out that Anderson's (1983) explanation in terms of declarative knowledge is unsatisfactory because it does not conform with the known facts of L2 acquisition. Anderson argues that linguistic forms are first represented as explicit knowledge, and then become implicit knowledge. This does not correspond with the known fact that a second language can be acquired subconsciously. 


\section{CONCLUSION}

It is clear that the search for a SLA theory is a complex issue. There is no single comprehensive theory of SLA; all that we have at present are a number of partial and incomplete accounts. It would indeed be difficult for one theory to account for the entire range of second-language phenomena. The trend in SLA research has been to move away from a general theory of SLA to theories of more limited scope. In addition, it is clear that the study of SLA must be approached from a variety of perspectives. I have tried to illustrate the relevance of a linguistic perspective (from generative linguistics), a sociolinguistic perspective (from functional linguistics), and a cognitive perspective (from cognitive psychology). And these are not the only disciplines which can shed light on the problem: SLA can also be approached from neurolinguistics, discourse analysis, and social psychology. Each of these disciplines can make a contribution to SLA theory. Gass (1989:500) points out that " ... it is only with a multiplicity of perspectives that we can begin to unravel the mystery of SLA". These different perspectives make up a "modular" approach to SLA research, in which different theories may complement each other. For example, it is possible to argue for the existence of innate universal linguistic properties of language, and at the same time, to argue that the language leaming process involves the utilization of problem-solving and general cognitive skills, as well as social skills, to achieve communicative goals and intentions (McLaughlin 1987:156).

It is clear that the applied linguist has a complex task. He must tum to various disciplines which can shed light on the problem of SLA. But his task does not end here; he must relate theory to practice. The theories of SLA must be related to the teaching of second languages. A further problem confronts the applied linguist here: there is no direct link between SLA research and language teaching; no clear implications for second language teaching to be drawn from the study of SLA. Teaching is not the same as acquisition. But on the applied linguist rests the responsibility to establish this link, as he always has an obligation to attempt to answer practical questions in the light of the best available evidence. All theories of SLA may have something to say to the language teacher, and it is the task of the applied linguist to articulate this in such a way that it is accessible to the teacher. The task of the applied linguist is to sketch a balanced approach in which input, interaction, instruction, practice and intemal processing all interact in the teachinglearning process. But there are still too many gaps in our knowledge for the applied linguist to be too prescriptive about teaching procedures.

\section{BIBLIOGRAPHY}

ANDERSON, J. 1983. The architecture of cognition. Cambridge, Mass.: Harvard University Press.

BIALYSTOK, ELLEN. 1988. Psycholinguistic dimensions of second language proficiency. In Rutherford, W. and M. Sharwood-Smith (Eds). Grammar and second language teaching. Rowley, Mass.: Newbury House.

BLOOMFIELD, L. 1933. Language. New York: Holt.

CHOMSKY, N. 1976. Reflections on language. London: Temple Smith.

CHOMSKY, N. 1980. Rules and representations. Oxford: Basil Blackwell.

CLAHSEN, H. and P. MUYSKEN. 1986. The availability of Universal Grammar to adult and child leamers: as study of the acquisition of German word order. Second Language Research 2:93-119. 
COOK, V.J. Chomsky's Universal Grammar and second language learning. Applied Linguistics 6(1):2-18.

ELLIS, R. 1990. Instructed second language acquisition. Oxford: Basil Blackwell.

FLYNN, SUZANNE. 1985. Principled theories of L2 acquisition. Studies in second language acquisition 7:99-107.

GASS, SUSAN M. 1989. Language universals and second-language acquisition. Language Learning 39(4):497-534.

JOHNSON, K. 1982. Communicative syllabus design and methodology. Oxford: Pergamon.

LARSEN-FREEMAN, DIANE and M.H. LONG. 1991. An introduction to second language research. London: Longman.

LOVE, N. 1990. Chomsky's theory of language acquisition. South African Journal of Linguistics 8(4):164-173.

McLAUGHLIN, B. 1987. Theories of second language learning. London: Edward Amold.

McLAUGHLIN, B. 1990. Restructuring. Applied Linguistics 11(2):113-128.

TARONE, ELAINE. 1990. On variation in interlanguage: a response to Gregg. Applied Linguistics 11(4):392-400.

TAYLOR, D. 1988. The meaning and use of the term "competence" in linguistics and applied linguistics. Applied Linguistics 9(2):148-168.

WHITE, LYDIA. 1989. Universal Grammar and second language acquisition. Amsterdam: John Benjamins. 